\title{
Research on Character shaping in Animated film Monkey King Chuang Chen
}

School of art,Zhengzhou University of Industry Technology,Zhengzhou451100,China. 474570630@qq.com

Keywords: Character personality; character design; motion design; Animation;

\begin{abstract}
The animated character as an important element in animated films, Undertake the task of deducting stories, pushing the story development, Character shaping is the core of whole role shaping, Different Characters have different feeling to audience and Characters constantly Spread emotion direction of animated films, character design, motion design, color design is an important means to carry out the role of personality shaping. In this paper, analysis Characteristic of Character shaping based on the film Monkey King to provide a theoretical for the study of animated Character shaping and a reasonable design basis for the Character shaping in animation design.
\end{abstract}

\section{Introduction}

Animated characters are movie actor in animation, it is a virtual character designed by designer through the artistic creation, Animated characters have a very important status because the animation stories revolves around the characters; Character of animation character is a psychological characteristics which revealed in the way to other people and Other things in films ,it was anthropomorphic and designed by designer based on the needed of stories and stories move, such as courage, justice, and cowardly [1].

Monkey King as an excellent home-made cartoons, its successful animated character creation role played a crucial role to attract the attention of the audience through the appropriate role. This paper focuses on Research the Character shaping in Animated film Monkey King through three aspects as character design, color design and motion design.

\section{Character design and animation character shaping}

Animation design refers to the way of artistic techniques to show the image of the body shape and spatial modeling in animation design process, animation design focuses on the animated character body shape and other details of modeling, the animation design often use exaggeration, distortion and other techniques to show the role of personality because highly hypothetical of animated characters, animated character modeling allows the audience quickly grasp the role of personality characteristics and identify with the characters[2] .

The Proportion of Head and body refers to the ratio between the length of head and body,it is an important design aspects in animation design . Different head and body proportions have different characteristics. accordance with the rule of animation modeling design, the ratio is two means $\mathrm{Q}$ version role,who have rich, exaggerated facial expressions;it is children if the the ratio is four;if the the ratio is severn means the Standard body height ,it is ok for realist style ; role taller role modeling for performance strong, burly roles. The Monkey King is realistic style because his eight head body and in line with people's aesthetic requirements for the body, so that the Monkey King with a more close to human physical characteristics,through the proportion of this design, weakening characteristic of monkey and the Monkey King have a double feature with a monkey and person,it is more easily accepted by people in today's humanitarian mainstream trends; the children who name is Liuer Jiang have a four head body , this ratio means lovely, lively, can bring endless joy and different with the image in traditional view. 


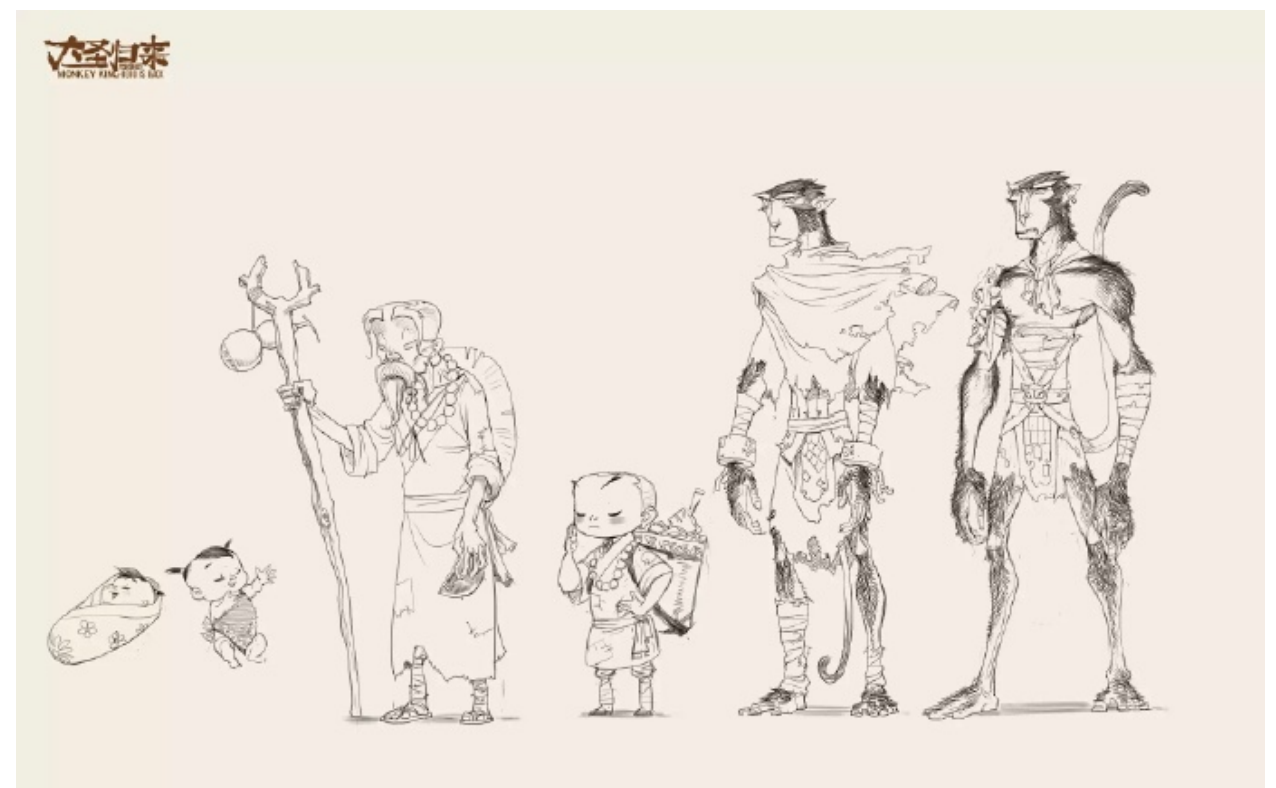

Fig. 1 Character design of Monkey King

Most of the time the animated character's emotions expression through facial expressions, character's facial expressions is an important manifestation of the character, so the character facial animation plays an important role in the animation character design and Character personality. [3]Accordance with the rule of facial expressions design, virtuous character facial features to stretch more and the villain's design is more tight.The monkey king who 's facial features is rectangular and angular were directly designed from a person's facial features,it 's properly give expression to monkey king's rebellious, avenging character outside the face and namely that the performance of the King's personality,this way meet the aesthetic needs of the people;the big devil who 's facial features is rotundity, slender eyebrows, aquiline nose, thin lips, gives a feeling of hideous evil.

\section{Motion design and animation character shaping.}

Motion design is the design of movement patterns and it 's largely reflects the personality of the animated character 's, such as performance unsociable, passive role's action is generally slow and it will be faster and exaggerated by lively, outgoing roles. must be accordance with the role of personality accurately so that the role of personality to get full performance. Motion design mainly from the exaggerated movements and rhythmic which lets animated characters show more lively and quickly convey emotion to the audience[4].

The Monkey King's motion were exaggerated and Rhythm control in the film,such as the exaggerated facial expressions and movements to express emotion flustered when faced to the chatter boy;the deliberately alienate expression and Expression when contact and rescue liuer Jiang is entirely a Chinese standard of young people, through the action design of the Monkey King showing the King from the beginning arrogant and unyielding character to finally honed moral courage ,it just the underlying message of film[5] .

liuer Jiang motion designed is in accordance with the role of action for children, always exhibit a curious and straightforward, for example,the lively and serious action when he tale to the Monkey King, bounce way of walking, the nose almost flow into the mouth , optimistic and confident movements when face the danger, this designed get the audience's love and recognition.

Meanwhile, the other characters in the film is also representative,for example,the pig moves slowly showing his lazy and timid;the Land grandpa was so cute because each time when they are drilled it is circling out;the monster's movements are very sensitive showing monster's terrible and evil.

\section{Color design and animation character shaping}


Color design is the color of animation designers give to cartoon, with the development of the plot, the role of psychological also can produce pleasure with plot twists, tension, fear and helpless. Animation, as well as other colour itself has no emotional colour,the emotion of animated characters is people through long-term accumulation of the subjective feeling of life, Such as red represents happiness, blue represents the blue and white represents elegance, colour can make people produce psychological associations, can let the audience psychological and emotional resonance in the process of viewing, the role of color design can performance character of personality traits. the color design of Scene can foil the emotion and psychological change of characters, holding the emotion performancer have a important means for performance the psychology of animation characters.

The color design is an important aspect of animation character design, the colour of animation role can let the audience get the first impression of the character,and clothing, skin tone, hair color can reflect the characteristics of animation characters ,in the films,the Monkey King's is with red dress in front of the transformation and his hair is the lack of gloss and fleeciness and messy yellow brown, barefoot, reflects the king is an ordinary monkey, no ability and responsibility like a Middle aged uncle. After he remove seal,the king dressed the silver armor, deep and elegant hair, all modelling is given priority to with red and gray,it has a sharp contrast with the front,this reflects the king's inner emotional changes at this time and he is a hero with a huge energy. We can see from the contrast between different stages the same characters color design and the character's personality change is inseparable, through the color change can convey different information to the audience then bring the audience into the animation in the plot .

Animation scene is a scene of animation role performance which color design can foil the emotional and psychological changes of character, the visual change of animation scene is associated with che animation character personality and psychological changes. when the character is positive and optimistic, we can use red, yellow, green as a scene of color; We can use the purple, black, dark blue, dark green with low purity and lightness color when the character was depression and negative; a highly contrast color design can be used when the character was angry because the comparative and strong colour will burst out strong emotion.

In the film,when the Liuer Jiang was chasing by che monster,a violet and dark gray colour was use by che scene,this colour gives the great depression and a sense of urgency and showed a dangerous atmosphere,in this time the audience psychological nervous feeling will arise; the whole scene is given priority with bright green, blue, showing the emotion of a peaceful, full of hope and let audience feel mental relaxation ,at the same time chis scene color design also promote the development of the story and performance the subtle changes in the relationship between the and Liuer Jiang;it was stark contrast scene color design between the enie appeared the whole scene as dark gray and the whole scene is golden yellow after the Monkey King finally remove seal,it shows showed up the conflict between good and evil,and justice triumphalism,the Monkey King show the immeasurable power whe he dressed in silver armour, fiery red hair and cloak, at this time to give the audience is the heroic image of Monkey King.

\section{Summary}

Through analysis and research, we can find good animation film emotion mainly through animated characters, a successful action design and modelling design, color design should be consistent with the theme of the film, animation designers gives animated unique personality through the animation role model[6].

In conclusion, a good animated characters will inevitably has its own unique personality traits,a good animation film will give people leave deep impression because the character shaping and become a kind of symbolic mark. the success character can bring success to the animated film. Chinese must be good at summarizing and found ,we must seeks to take the new breakthrough on animation character shaping,we believe that Monkey King -a excellent animation film is only the beginning rise of the Chinese animation. 
Advances in Social Science, Education and Humanities Research, volume 87 


\section{Acknowledgments}

This paper is the periodical results of the project(Innovation in the mechanism of high skilled personnel training in Henan Province NO:16A880013)which is the key project of Colleges and Universities in Henan province, China.

\section{References}

[1] Guofeng $\mathrm{Hu}$.Analysis of the relationship between the character of the cartoon and the audience[J].Movie literature.2014,No.5,p. 60-61.

[2] Haoquan Teng.Discussion on the influence of role modeling design on character shaping. Film Review.2011,No.1,p. 15-16.

[3] Kang Kang.Talking about the animation performance.Art Education Research,2015,No.5,p. 83-84.

[4] PengChen .Effects of characteristic motions in animation film.Movie iterature.2015,No.3,p. 83-85.

[5] JianWu.Discussion in action design of animation role performance. Art Criticism,.2013,No.3,p. 13-116.

[6] QingLu.The "experience" performance of the cartoon character.Art Review.2015,No.10,p. 127-129. 